\title{
Autologous Ad-CD154-Transduced CLL B Cells
}

National Cancer Institute

\section{Source}

National Cancer Institute. Autologous Ad-CD154-Transduced CLL B Cells. NCI

Thesaurus. Code C68842.

An autologous tumor cell vaccine containing chronic lymphocytic leukemia (CLL) B cells transduced with an adenoviral vector carrying chimeric CD154 (ad-CD154) with potential antineoplastic activity. Administration of autologous ad-CD154 transduced CLL B cells may result in increases in the numbers of leukemia-specific CD4+ T cells and high serumlevels of IL-12 and IFN-gamma. Due to ligation of CD154 to CD40 on CLL cells, this agent may induce CLL cells to express the proapoptotic molecule BID and death receptors CD95 (Fas) and DR5, rendering CLL B cells first resistant and then sensitive to Fasmediated apoptosis. In addition, autologous ad-CD154 transduced CLL B cells may induce $\mathrm{MHC}$ class I-dependent cytotoxic T lymphocyte $(\mathrm{CT} L)$ responses against autologous leukemia cells. CD154 is a type II membrane glycoprotein and ligand for CD40; both molecules are important in cognate co-stimulatory cell-cell interactions. 